\title{
Variations in flocking behaviour from core to peripheral regions of a bird species' distribution range
}

\author{
Carlos Camacho
}

\begin{abstract}
Flocking behaviour in birds reflects the outcome of a momentary trade-off between increased foraging efficiency and improved predator avoidance. However, these changing patterns remain poorly known at any spatial or temporal scale. The aim of the present study was first to investigate seasonal fluctuations of flocking behaviour throughout the entire distribution range of a species and secondly to explore behavioural responses to daily temperature variations. From 2000 to 2010, sightings of Peruvian Thick-knees (Burhinus superciliaris) were collected throughout Ecuador, Peru and Chile. There were strong differences in flocking behaviour between Chilean and Peruvian populations. While Thick-knees occurred into few large year-round flocks in Chile, flock occurrence was highly seasonal in Peru, where group size grew gradually from loose flocks at the end of the breeding season to a few large ones by the middle of the year. Time of day seemed not to affect the species detectability but was negatively related to flock size. Variations in the flocking behaviour of Peruvian Thick-knees throughout its distribution range suggest that aggregation patterns might indicate individuals responding to seasonally fluctuating ecological pressures, such as those derived from predation, foraging or climate.
\end{abstract}

Keywords Flocking behaviour - Antipredator strategies · Conspicuousness $\cdot$ Peruvian Thick-knee $\cdot$ Burhinus superciliaris

C. Camacho $(*)$

Department of Evolutionary Ecology, Estación Biológica de Doñana-CSIC,

Av. Américo Vespucio, 41092 Seville, Spain

e-mail: ccamacho@ebd.csic.es
Introduction

Flocking behaviour in birds is a widespread phenomenon in temperate regions and tropics. Forming assemblages usually results in a conflict of opposing options explained by the selective forces derived from predation and feeding efficiency (Morse 1977; Herrera 1979). In nearly all gregarious species, assemblages favour higher individual survival and reproductive success (Faaborg and Patterson 1981, Brown et al. 1982). Nevertheless, the balance between costs and benefits of flocking may not always yield an overall fitness benefit (Leonard et al. 1989, Du Plessis et al. 1995, Andrews 1997). Flocks can also lead to intraspecific competition (Sasvári 1993) and increase detectability by predators (Treisman 1975; Marzluff and Balda 1992). These disadvantages could outweigh benefits especially while nesting, when birds are not free to perform forced displacements.

The Peruvian Thick-knee (Burhinus superciliaris) is an uncommon species that is found from the southern extreme of Ecuador through Peru to the northern border of Chile, where it is strongly restricted to dry agricultural areas and semi-arid grass and scrublands near coasts (Koepcke 1964). While gregarious behaviour has been previously studied in other congeneric species (Andrews 1997; Green et al. 2000), little is known about behavioural traits in Peruvian Thick-knees.

Several flock features have been thoroughly investigated in mixed species flocks of diurnal passerines (e.g. Morse 1977; Herrera 1979; Hutto 1988) while the flocking behaviour of nocturnal birds remains poorly documented. Furthermore, most studies in flocking behaviour have usually focused on the balance between predation avoidance and foraging enhancement, whereas the factors leading to variations in flocking behaviour or its potential functionality have been 
almost overlooked. In this paper, I present data on seasonal fluctuations in flocking behaviour of Peruvian thick-knees and variations throughout its world range and discuss possible mechanisms driving these patterns.

Materials and methods

Study area

The Peruvian Thick-knee inhabits restricted areas of southwestern Ecuador and the deserts of coastal Peru and northern Chile. This continuous belt is under the influence of the Humboldt Current, which maintains temperature homogeneity along the entire latitudinal extent of these deserts. Despite this pattern of temperature stability, topography, climate and vegetation of each desert are slightly different (Rundel et al. 1991). Southwestern Ecuador is outside the bioclimatic region of the ChileanPeruvian Pacific coastal desert and, in contrast to northern Chile, seasonality in rainfall can be found in Peru, which is sharper in northern than central-southern Peruvian localities. In the dry temperate tropical deserts of north Peru, Thick-knees were usually sighted in floodplain areas dominated by scattered xerophytic shrubs (Capparis ovalifolia) and scarce tree stands (Parkinsonia aculeata, Acacia macracantha). In coastal central and southern Peru, the climate is warm with scarce precipitations from May to November. Here, habitats where Thick-knees were sighted consisted of bare stony plains and low hills or sandy areas with scattered patches of saltgrass (Distichlis spicata). The northern Chile climate is characterized by wide daily temperature extremes and sharp droughts. In this area, Thick-knees were usually seen in flat bare sandy areas with scattered small clumps of xerophytic vegetation and sparse grass or in plowed fields, old corn fields or even young fruit tree drops. It must be noted that in contrast to Peru, which is the ancestral distribution area of the Peruvian Thickknee, Chile seems to be a fairly recent extension of the species' range (Aguirre et al. 2006).

\section{Data collection}

Beginning in spring 2010, an exhaustive search for photographs or reports on Peruvian Thick-knee was conducted through contemporary internet search engines, using the key-phrase 'Burhinus superciliaris' and other related phrases including the species' common name in three languages. The available information on Peruvian Thickknee observations was extracted from each report, and the references were reviewed for additional sources. At a second stage, all the authors of the downloaded reports and photographs and other potential observers were con- tacted by e-mail between spring and autumn 2010. Overall, 54 experienced observers (scientific researchers, birding guides, photographers and local or international observers) were asked to collect their additional unpublished daylight sightings of Peruvian Thick-knees from its world distribution range in the last 10 years, in order to complete a questionnaire form which requested location, date, time of day and group size, specifying breeding when confirmed. Sighting data were grouped into 24 fortnights (1-year period) and, according to the differences between studied sites (see above), reports from the three countries were grouped separately. However, the lack of reports from the declining Ecuadorian population prevented from getting a data collection as large as those from Chile or Peru.

Both in Chile and Peru, most breeding reports (93.3\%, $\mathrm{n}=15$ ) took place between October 15 and February 15, so the year was divided fortnightly into the breeding season (hereafter BS; 15 October to 15 February) and the nonbreeding season (hereafter NBS; 16 February to 14 October). For bird numbers, observations were categorized into pairs and flocks, depending on whether single pairs or groups of individuals (irrespective of their size) were recorded. Due to the high difficulty of detection of cryptic species like Thick-knees, a pair was simply considered to be one or two individuals sighted together whereas any group of more than two individuals gathered or following each other was considered to be a flock. There were no reports of mixed species flocks but all roosting groups recorded were monospecific. Consecutive observations $(<24 \mathrm{~h})$ from the same locality were omitted from analysis to reduce the likelihood of counting already recorded groups twice and thus avoiding pseudoreplication.

\section{Statistical analysis}

All statistical procedures were computed using the software package R, v. 2.12 (R Development Core Team 2010). Since data were not normally distributed, nonparametric statistical methods were employed for comparative analyses. Variations in flocking behaviour were analyzed using the General Linear Model procedure (with Poisson distribution for errors). For the analysis of group size differences between countries, the Mann-Whitney $U$ test was performed. The $x^{2}$ test was applied to compare the flock occurrence between seasons in both countries. The Spearman correlation test was used to measure the effect of time of day on flocks encounter rate and flock size detected by se same observer during 31 sighting episodes in the same area in northern Chile from 8:00-18:00 hours local time (there were no available data from Peru). Ecuador was finally excluded from the analyses in order to the small sample size. Differences were considered to be significant at $\mathrm{p}<0.05$. All values are reported as medians (Q25-Q75). 
Results

Overall, 133 observations of 1642 Peruvian Thick-knees were collected from January 2000 to October 2010 throughout the entire species' distribution range. Most records were from Tarapacá region in northern Chile and several localities in Peru (48.1\% and $46.6 \%$, respectively), whereas only a few (5.3\%) were from Santa Elena in southwestern Ecuador. Neither large flocks nor breeding records from Ecuador were reported (number of individuals seen together $=3(2-3))$. Nevertheless, a flight-capable fledgling observed with two adults gives firm evidence of breeding therein.

Throughout the year, group size ranged from one to 53 birds in Chile and Peru, although there were strong differences in flocking behaviour between the countries. The number of individuals seen together fluctuated slightly between seasons in Chile (8 (3-27.3) and 9.5 (2-29.3)), in BS and NBS, respectively $\left(F_{1,62}=3.64, p=0.056\right)$, whereas those fluctuations were much more pronounced in Peru (2 (2-4.8) and 16 (5-20.3)), in BS and NBS, respectively $\left(F_{1,60}=255.62, p<0.0001\right.$; Fig. 1). Accordingly, flock size during BS was significantly different between Chile and Peru ( $U=302.5, p<0.001)$. In fact, while Thick-knees were frequently seen grouped into few large year-round flocks in Chile $\left(X^{2}=0.12, d f=1, p=0.732\right)$, those flocks were almost restricted to the NBS in Peru $\left(X^{2}=13.76, d f=1, p<0.001\right)$ where group size fluctuated gradually from several loose
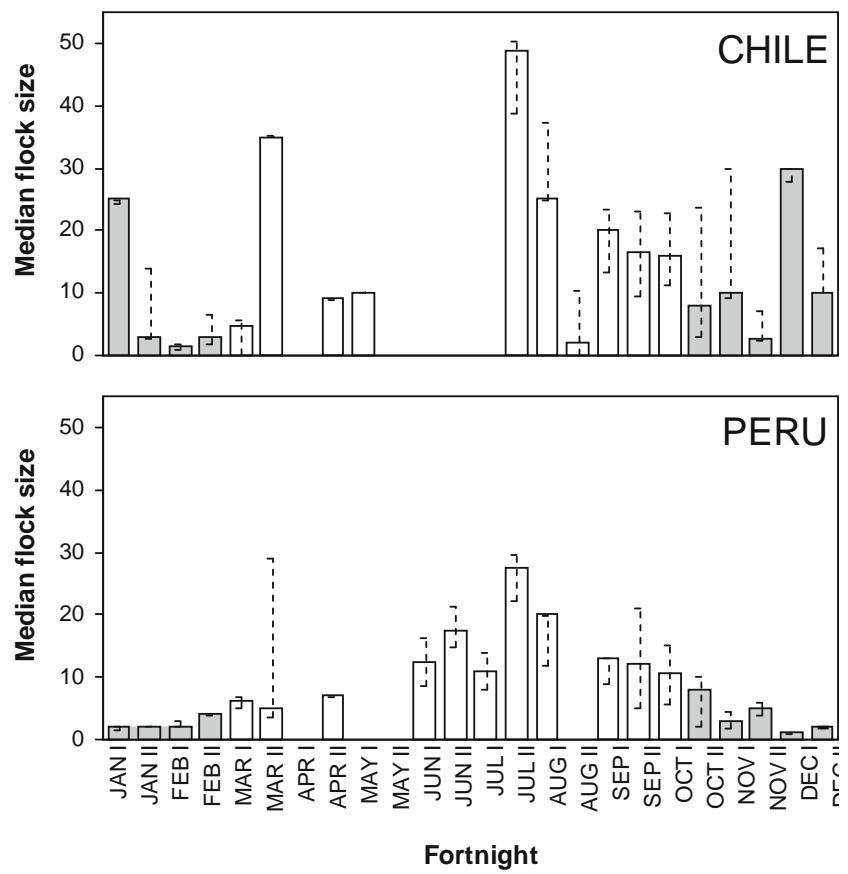

Fig. 1 Fortnightly fluctuation in flock size of Peruvian Thick-knee in Chile and Peru. Bars represent median values (BS, shaded bars; NBS, open bars) while dotted lines show the difference between the first and the third quartile (Q25-Q75) small flocks close to the end or the beginning of the BS to a few medium-sized ones by the middle of the year (Fig. 1, Table 1). Therefore, variations in flocking behaviour between both countries were attributable both to seasonal versus permanent flock occurrence and to the prevalence of large versus medium-sized flocks, even during NBS.

Time of day had no effect on flocks encounter rate in Chile $\left(r_{S}=0.05, p=0.892\right)$ but a significant negative correlation was found between time of day and flock size detected by the observer $\left(r_{S}=-0.36, p=0.046\right.$; Fig. 2). Therefore, high temperature variations along the day seem no to affect the species detectability but may cause the flock sizes to be underestimated.

\section{Discussion}

The flocking behaviour of Thick-knees differed significantly between populations from Chile and Peru. Seasonal fluctuations in flocking behaviour have been previously reported for Burhinidae (Blakers et al. 1985; Fabien 1999; Tissier 2007) but very few authors mention the persistence of flocks throughout the whole year (Schodde and Mason 1980; Andrews 1997) and none of them report variations in the aggregation patterns along the whole distribution range of a species.

Peruvian Thick-knees are crepuscular and nocturnal, being most active at dusk. During daylight, they tend to be fairly gregarious and typically gather to roost. However, the absence of nocturnal fieldwork prevents from knowing if gregariousness also holds after dusk when birds depart the roosts (Ortiz-Crespo and Carrión 1991). Selective forces driving flocking in birds have been usually grouped into those derived from predation avoidance or foraging enhancement. However, it still remains unexplored to what extent each factor has contributed to yield local or seasonal variations in the performance of flocking behaviour for a given species. In southwestern Ecuador, all Peruvian Thickknees seen at nighttime were either foraging alone or together with another Thick-knee in nearby areas from the daytime roosting sites (C. Camacho, unpublished data). This might indicate that roosting flocks split up to forage at dusk and so individuals probably avoid or reduce mutual disturbance, enabling them to increase foraging efficiency. Accordingly, flocking behaviour in Peruvian Thick-knees may be explained by considering mainly the selective forces derived from predation-related advantages. Flocking certainly increase detectability by predators though the size of flocks are closely related to advantages of predator avoidance (Stinson 1980), achieving an optimum at intermediate values of flock size (Giraldeau and Caraco 2000). This 'optimum flock size' may partly explain the temporal fluctuations in flocking behaviour in Peruvian 
Table 1 Summary of the observations of Peruvian Thick-knee from Ecuador, Peru and Chile during the breeding (BS; 15 October to 15 February) and non-breeding season (NBS; 16 February to 14 October)

\begin{tabular}{|c|c|c|c|c|c|c|}
\hline & \multicolumn{3}{|c|}{ Breeding season } & \multicolumn{3}{|c|}{ Non-breeding season } \\
\hline & Ecuador & Peru & Chile & Ecuador & Peru & Chile \\
\hline Locations & 1 & 14 & 4 & 4 & 15 & 4 \\
\hline Breeding reports & 0 & 5 & 9 & 0 & 0 & 1 \\
\hline Flocks & 1 & 13 & 29 & 3 & 29 & 18 \\
\hline Pairs & 0 & 17 & 9 & 3 & 3 & 8 \\
\hline Birds & 7 & 110 & 564 & 14 & 511 & 436 \\
\hline Median flock size & 7 (7-7) & $5(4-8)$ & $19(6-30)$ & $3(3-3)$ & $18(7-21)$ & $22.5(9.3-33.8)$ \\
\hline
\end{tabular}

populations, where flocks are characterized by intermediate size and a marked seasonality. However, Peruvian Thickknees avoid forming nesting assemblages or just aggregating during the breeding season in Peru. Living close to other conspecifics certainly enhances conspicuousness to predators (Treisman 1975; Marzluff and Balda 1992), especially while nesting. On the other hand, nesting in aggregations improves efficiency in predator avoidance by increasing the vigilance rate of the group (Lima and Dill 1990). However, Myers (1980) suggested that the benefits of flocking are probably related to reducing the rate of attack success, not to increase the likelihood of detecting a predator. Thick-knees usually occur near coasts, in bare dry areas (Koepcke 1964; Canevari et al. 2001, this study), where there is scant cover to provide hiding places and protection from predators. Thus, breeding assemblages in this species may provide predators with more chances to develop an accurate search image and improve their prey finding and capturing techniques, which might result in higher rates of predation on flight-incapable fledglings and lower fitness. A periodic balancing in the costs of flocking by breeding individuals could explain the large seasonal fluctuations of flock sizes in Peru, where flocks progressively disband as the breeding season approaches.

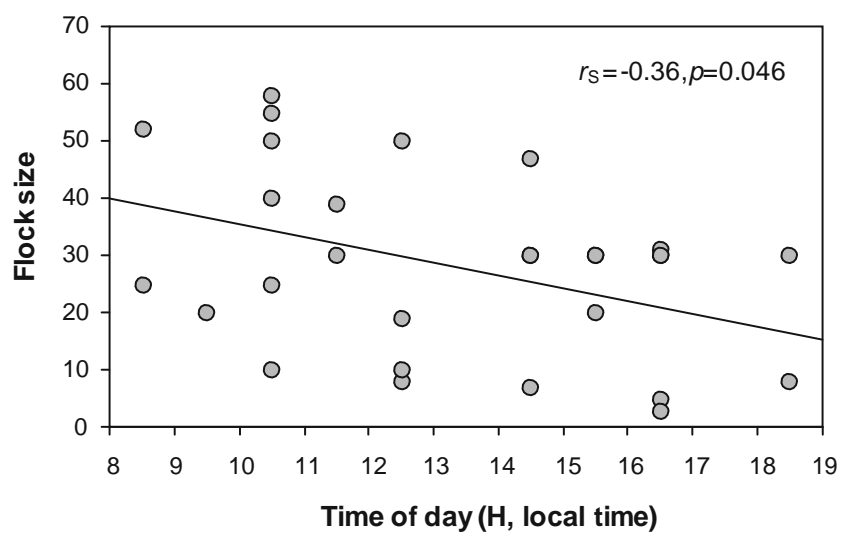

Fig. 2 Effect of time of day on flock size of Peruvian Thick-knees detected by the same experienced observer in the same area in northern Chile
By contrast, Thick-knees occur in flocks even during BS in Chile. There could be several explanations for the lack of fluctuation in flocks of the Chilean populations. Andrews (1997) reported that permanent flocks in B. grallarius were formed by birds that did not attempt to breed and moved between non-breeding groups throughout the year. Cullen and Robertson (1999) suggested that wintering juveniles' shorebirds gathered at common feeding grounds for some time until gaining the experience necessary to perform complex antipredator group behaviours proficiently. In Chile, breeding reports associated to flocks are limited, supporting that Thick-knees gathered during the BS are probably non-breeding, unmated birds. Non-breeding birds are free to move through other territories in case of resources' depletion or predators' harassment. Hence, the advantages derived from flocking behaviour might outweigh costs for unmated birds which could explain large flocks' prevalence at the southern edge of its world range. Though flocking behaviour has both costs and benefits, post-nuptial assemblages in Peru and stable flocks in Chile suggest that benefits of aggregating to non-breeding flock mates year-round or congregating after breeding might outweigh costs derived from intraspecific conflicts.

On the other hand, in contrast to the declining population trend in Ecuador (Camacho 2010), the north of Chile seems to be a fairly recent range extension of Thick-knees towards the south (Aguirre et al. 2006). At the southern edge of its world range, the number of records of this species has increased significantly during the last decades in Tarapacá (Miranda et al. 2001). There, Thick-knees' densities are the highest, as also reported for other Burhinidae (e.g. Green et al. 2000). Furthermore, Chilean Thick-knees not only aggregate in large numbers in BS but also their flocks are still larger than the loose flocks observed outside BS in core regions of the species' distribution range. In Chile, large flock sizes and high proportions of unmated birds not linked to nesting sites and presumably free to displace and explore new habitats suggest that groups of unmated birds may become a potential source for a progressive expansion of the southernmost boundary of the species distribution range. 
An alternative hypothesis to explain the variations observed in the flocking patterns of Peruvian Thick-knees could be also considered. In Chile and Peru, the BS seems to be restricted to the same period even though, in contrast to north Chile, slight weather seasonality can be found in Peruvian localities. The spatial arrangement of flocks might be also affected by the habitat structure and climate conditions, which may bias the detection of entire flocks even by experienced observers. Desert birds respond to heat stress by drastically reducing activity during the hottest parts of the day and selecting cool shaded microsites (Wolf 2000). In bare sandy soils, where there are not even clumps for birds to take cover, Peruvian Thick-knees stand out strikingly against the bare background as they remain gathered to confront the hottest time. As habitat heterogeneity increases through closer ground cover of shrubs and grass, wide annual or daily temperature variations may condition the aggregation patterns of Thick-knees. Birds exposed to increasingly hot environmental temperature during the day would require to seek thermal refuges, so large flocks may split up into loose groups to roost under canopy-shaded sites.

The data above suggest that fluctuating flocking behaviour in Peruvian Thick-knee may reflect individuals responding to different ecological pressures. Group living seems to offer several benefits mainly to non-breeding birds, so seasonal flocking dynamics might be related to inconspicuousness requirements of breeding birds and could be also affected by habitat heterogeneity and climate conditions. Disbanding of assemblages presumably functions to decrease conspicuousness and thus minimize predator's efficiency. Therefore, the inconspicuous nature of Burhinus might be connected not only to plumage colour and a very low activity during daylight hours (Karavaev 1998) but also to circadian and seasonal fluctuations in its flocking behaviour.

Finally, it should be noted that the relative abundance of cryptic species is often underestimated (Thiollay 1999). Therefore, the difficulty of detection of Thick-knees combined with a behavioural response to daily temperature variations and other ecological features of this species, such as low densities and seasonal flocking behaviour, represent serious barriers to obtain accurate estimates of abundance.

Acknowledgements S Woolley, J Casson, L Sirvio, M Shardlow, A Earnshaw, E del Solar, J Mazzotti, G Lavaty, D Cook, E Lee and J Cabrera provided their sightings from Peru. J Aguirre, MR Ávila, A Grosset and L Miranda provided their observations from Chile. N Athanas, F Schmitt and M Reid provided information from both countries and S Torres kindly provided his sightings from Ecuador. I am especially grateful to B Knapton and A Tabini, who provided most observations and site descriptions from Chile and Peru, respectively and to S Sánchez, who helped during data collection. J Potti and P Jordano thoroughly reviewed earlier drafts of the manuscript and $\mathrm{J}$ Aguilar, JM Jordão, JF Maselló and an anonymous reviewer improved this article with their constructive comments.
Conflict of interest statement The author declares that he has no conflict of interest.

\section{References}

Aguirre J, Demanguel R, Canepa A (2006) Apuntes sobre la nidificación del Chorlo Cabezón (Burhinus superciliaris) en el norte de Chile. Bol Chil Orn 12:36-37

Andrews L (1997) The breeding behaviour and success of the Bush Stone-curlew Burhinus grallarius on Magnetic Island. Honours Thesis. James Cook University of North Queensland

Blakers M, Davies SJJF, Reilly PN (1985) The Atlas of Australian Birds. Royal Ornithologists Union Melbourne University Press

Brown JL, Brown ER, Brown SD, Dow DD (1982) Helpers: effects of experimental removal on reproductive success. Science 215: 421-422

Camacho C (2010) Distribución y estado de conservación del Alcaraván Peruano (Burhinus superciliaris) en Santa Elena, SO Ecuador. Bol Chil Orn 16:66-73

Canevari P, Castro G, Sallaberry M, Naranjo LG (2001) Guía de los Chorlos y Playeros de la Región Neotropical. Asociación Calidris, Cali

Cullen S, Robertson GJ (1999) Temporal changes in the antipredator flocking behavior of wintering shorebirds. Waterbirds 22(1):156159

Du Plessis MA, Siegfried WR, Armstrong AJ (1995) Ecological and life-history correlates of cooperative breeding in South African birds. Oecologia 102:180-188

Faaborg J, Patterson CB (1981) The characteristics and occurrence of cooperative polyandry. Ibis 123:477-484

Fabien S (1999) Arrival and departure dates and phenology of the postnuptial gathering of Stone Curlew (Burhinus oedicnemus) in Alsace. Ciconia 23(2):41-50

Giraldeau LA, Caraco T (2000) Social foraging theory. Princeton University Press, New Jersey

Green RE, Tyler GA, Bowden CGR (2000) Habitat selection, ranking behaviour and diet of the Stone Curlew (Burhinus oedicnemus) in southern England. J Zool 250:161-183

Herrera CM (1979) Ecological aspects of heterospecific flocks formation in a Mediterranean passerine bird community. Oikos 33:85-96

Hutto RL (1988) Foraging behavior patterns suggest a possible cost associated with participation in mixed-species bird flocks. Oikos 51:79-83

Karavaev AA (1998) Daily activity of Stone Curlew Burhinus oedicnemus during the breeding period. International Wader Studies 10:329-332

Koepcke, M (1964) Las aves del Departamento de Lima. Maria Koepcke (Ed.) Lima

Leonard ML, Horn AG, Eden SF (1989) Does juvenile helping enhance breeder reproductive success? Behav Ecol Sociobiol 25:357-361

Lima SL, Dill LM (1990) Behavioral decisions made under the risk of predation: a review and prospectus. Can J Zool 68:619-640

Marzluff, JM, Balda RP (1992) The Pinyon Jay behavioural ecology of a colonial and cooperative corvid $\mathrm{T}$ and $\mathrm{AD}$ Poyser, London

Miranda L, Herreros J, Knapton B (2001) Observaciones de Burhinus superciliaris en la Región de Tarapacá. Bol Chil Orn 8:36

Morse DH (1977) Feeding behaviour and predator avoidance in heterospecific groups. BioScience 27:332-339

Myers JP (1980) Territoriality and flocking by Buff-Breasted Sandpipers: variations in non-breeding dispersion. Condor 82(3):241-250 
Ortiz-Crespo F, Carrión JM (1991) Introducción a las Aves del Ecuador Fecodes. Quito, Ecuador

R Development Core Team (2010) R: a language and environment for statistical computing R Foundation for Statistical Computing, Vienna. URL:http://www.R-project.org

Rundel P, Dillon M, Palma B, Money H, Gulmon L, Ehleringer J (1991) The phytogeography and ecology of the coastal Atacama and Peruvian deserts. Aliso 13(1):1-49

Sasvári L (1993) Colonial and solitary nesting choice as alternative reproductive tactics in birds. Etología 3:11-22

Schodde R, Mason IJ (1980) Nocturnal Birds of Australia. Lansdowne Editions, Melbourne
Stinson CH (1980) Flocking and predator avoidance: models of flocking and observations on the spatial dispersion of foraging wintering shorebirds (Charadrii). Oikos 34:35-43

Thiollay JM (1999) Responses of an avian community to rain forest degradation. Biodivers Conserv 8:513-534

Tissier D (2007) Note sur les rassemblements d'Oedicnemes criards dans le Rhone en 2006. L'Effraie 20:31-40

Treisman M (1975) Predation and the evolution of gregariousness I Models for concealment and evasion. Anim Behav 23:779-800

Wolf B (2000) Global warming and avian occupancy of hot deserts; a physiological and behavioral perspective. Rev Chil Hist Nat 73:395-400 